\title{
Variation in Bottom Soil Quality with Increasing Pond Age in Freshwater Aquaculture
}

\author{
Javairia Shafi ${ }^{1, *}\left(\mathbb{D}\right.$, Kashifa Naghma Waheed ${ }^{1}(\mathbb{D})$, Zahid Sharif Mirza ${ }^{1}(\mathbb{D}$, Muhammad \\ Zafarullah $^{1}$ (D)
}

${ }^{1}$ Fisheries Research and Training Institute, Lahore, Pakistan.

\section{How to cite}

Shafi, J., Waheed, K.N., Mirza, Z.S., Zafarullah, M., (2022). Variation in Bottom Soil Quality with Increasing Pond Age in Freshwater Aquaculture. Turkish Journal of Fisheries and Aquatic Sciences, 22(2), TRJFAS18305. http://doi.org/10.4194/TRJFAS18305

\author{
Article History \\ Received 21 October 2020 \\ Accepted 20 September 2021 \\ First Online 27 September 2021

\section{Corresponding Author \\ Tel.: +924236522895 \\ E-mail: javairiamalik@gmail.com}

\author{
Keywords \\ Particle size analysis \\ Soil salinity \\ Available phosphorous \\ Total phosphorous \\ Organic carbon
}

\begin{abstract}
Pond bottom soil quality is an interesting area to assess environmental impact of aquaculture. Aim of the present study was, therefore, to investigate effects of fish culture on quality of pond bottom soil. Ten excavated earthen ponds located in Lahore, Pakistan were divided into two groups; Group1: 23-32 years old and Group 2: 8-20 years old ponds. Mechanical and chemical methods were used to study particle size distribution and physico-chemical attributes of soil respectively. Surface sediment of ponds contained higher sand and lower clay content than that of deeper soil layers in both groups. $\mathrm{pH}$ of the soil was higher than 7.0 that ruled out the necessity to lime soil for neutralizing acidity. Salinity of surface soil was found to be significantly high $(P<.05)$ compared to that of deeper layers. Organic carbon in surface soil of Group 1 ponds (3.35\%) was significantly higher $(P<.05)$ than that of Group 2 ponds $(2.60 \%)$. Available phosphorous represented only $1-10 \%$ of total soil phosphorous. An interactive effect of pond age and soil depth was found on soil clay and electrical conductivity through factorial analysis. Results led to the conclusion that regular removal of sediment can maintain original quality of bottom soil.
\end{abstract}

\section{Introduction}

Aquaculture is a significant part of Pakistan's fishing sector with about 150 thousand tons per year fish production. However, the sector shows limited development despite of country's remarkable aquatic resources and Pakistan occupies $28^{\text {th }}$ rank among aquaculture producer countries of the world (The World Bank Group, 2018). It seems necessary to deal with the challenges of negative environmental impacts and poorly developed infrastructure for sustainable development of the sector. Nevertheless, freshwater aquaculture is progressing at a fast rate and Pakistan occupies $16^{\text {th }}$ position among World's Major Inland Aquaculture Producers with 158.8 thousand tons fish production reported during 2018 (FAO, 2020).

Almost all of the freshwater aquaculture in the country is based on pond culture (Hayat, 2005). However, pond owners are not well aware with the management of pond bottom soil during production cycles due to lack of relevant knowledge. Presence of excessive amount of labile organic matter in surface soil can lead to critical dissolved oxygen (DO) levels during culture periods. On the other hand, very low organic carbon content can influence bacterial and macrobenthic activity (Ndome et al., 2012) that in turn can affect the ecological processes of pond ecosystem. Pond fertilization depends upon the amount of nitrogen, phosphorous, carbon and potassium already present in the bottom soil (Boyd, 2003). Few earlier studies (Boyd et al., 1994; Thunjai et al., 2004) have reported the effect of pond operations and management practices on quality of soil. Mostly, the original pond soil is covered with a soft sediment whose physical and chemical characteristics are significantly different from those of indigenous soil. Accumulation of high sand content in surface sediment leading to excessive seepage of water and nutrients is also evident (Boyd, 1976). Quality of 
bottom soil affects the physico-chemical characteristics of overlying pond water which in turn has a significant impact on pond productivity (Thunjai et al., 2004). A few studies have also reported increase in soil phosphorous reservoir with increasing pond age (Tapader et al., 2017; Munisiri et al., 1995). Despite the fact that negative environmental impacts of aquaculture due to discharge of nutrient rich water in natural water reservoirs are well addressed in literature, the impact of aquaculture activities on pond bottom soil has not been investigated in detail (Munsiri et al., 1995).

In Punjab, Pakistan, aquaculture is dominated by polyculture of Major and Chinese carps. Water management involves water exchange and regular application of fertilizers and lime to improve its quality. Pond bottom is simply dried and ploughed to prepare it for culture of next crop after annual harvesting. Practices to assess chemical and physical changes in soil properties during fish culture are not common. Due to potential of bottom soil quality to change with pond age, it is necessary to analyze the soil quality on regular basis in ponds. This kind of analysis can guide the farmers to adopt the suitable management practices for soil conditioning that will in turn lead to improved fish production. Present study was, therefore, conducted to assess mechanical and chemical attributes of pond bottom soil of operational fish farms in Lahore district. Objective of the study was to determine the effect of aquaculture activities on pond soil quality and recommend suitable farm management practices. Furthermore, soil of potential sites for aquaculture was also evaluated to compare its quality with that of developed fish ponds and determine the effect of fish culture on pond bottom soil.

\section{Materials and Methods}

\section{Study Design}

An independent factorial experimental design was used for the study. Independent variables were pond age and soil depth with two and three levels respectively. Ten earthen ponds were randomly selected for the study and divided into two groups based on pond age. Group 1 included 5 ponds that were 23-32 years old and Group 2 consisted of 5 ponds of 8-20 years age. Ponds in Group 1 were labelled as LHR1-LHR5 and those in Group 2 were designated as LHR6-LHR10. Soil quality was evaluated through analysis of particle size distribution, organic carbon, $\mathrm{pH}$, electrical conductivity, total alkalinity, chloride, water soluble phosphorous, available phosphorous and total phosphorus of pond bottom soil.

Map of sampling sites is shown in Figure 1. Soil quality at four proposed sites for fish pond was also determined. Soil samples were collected in April-May, 2019 and analysed in Chemical Laboratory of Fisheries Research and Training Institute Lahore, Pakistan during July-December 2019. Information about farming practices adopted by the pond owners was also collected.



Figure 1: Map of freshwater fish ponds in Lahore district selected for study of bottom soil. 


\section{History of Fish Ponds}

Selected ponds were used for culture of Major carps, Chinese carps and Snakehead fish reared under freshwater semi-intensive culture system. Water surface area of ponds ranged from 0.8 acer to 3.0 acer. Ponds were filled with ground water and water level in all the ponds was maintained at 1.2-1.8 m. Inorganic fertilizers (urea, diammonium phosphate) at the rate of 3-50 kgacre $^{-1}$ and organic fertilizers (cow dung) at the rate of 100-1000 kgacre $^{-1}$ were used in the ponds fortnightly for primary productivity. Fertilizer requirement was estimated through the use of Sechhi disk visibility to adjust nutrient supply in the pond water.

Rice polish or commercially available fish feed was supplied at the rate of $5-10 \%$ of fish body weight on daily basis in ponds. Lime or gypsum was used during preparation of ponds for next crop or occasionally to disinfect the ponds. Fish production varied from 1000 kgacre $^{-1}$ year $^{-1}$ to 2000 kgacre $^{-1}$ year-1. During formal discussion with the pond owners, it was revealed that they were not familiar with significance of pond bottom soil quality in fish farming and did not adopt any soil management technique during culture except the addition of lime or gypsum. Moreover, the farmers never removed the surface soil sediment from the pond bottom to maintain its original characteristics.

\section{Samples Collection and Preparation}

Soil samples were collected with the help of a soil auger during the drying period of ponds. Three equidistant sampling points were selected from each pond with one point lying in the middle and two points covering the corners of pond bottom. Samples were collected in triplicate from each pond starting from surface up to the depth of $2 \mathrm{ft}$. with $1 \mathrm{ft}$. increment. Collected soil samples were stored in labelled polyethylene bags and transported to the laboratory. In order to compare the soil quality of developed fish ponds with that of new ponds, four potential sites proposed to be used for aquaculture in Lahore, Punjab, Pakistan were selected and soil samples were collected from surface up to the depth of $3 \mathrm{ft}$.

Preparation of soil samples involved air drying with subsequent sieving through a $2 \mathrm{~mm}$ mesh size screen. Prepared soil samples were stored in air tight containers till further analysis.

\section{Soil Analysis}

Hydrometer method was used to find particle size distribution of soil according to Bentone (2003). Briefly, a suspension of $50 \mathrm{~g}$ of air dried soil with $100 \mathrm{ml}$ of calgon solution was prepared in $1000 \mathrm{ml}$ glass cylinder and allowed to stand for 8 hours with subsequent shaking for 2 minutes. Volume of suspension was raised up to $1000 \mathrm{ml}$ with distilled water. Suspension was agitated vigorously and hydrometer reading was noted after $40 \mathrm{~s}$ and 2 hours of agitation. Clay, sand and silt content was calculated using appropriate formulae.

Organic carbon was measured using Boyd (1995) by heating the soil sample in a muffle furnace at 350 으 for 8 hours. To determine physico-chemical parameters of soil viz. total alkalinity, $\mathrm{pH}$, electrical conductivity (EC) and chloride content, soil: water suspension (1:2) was prepared following Pansu and Gautheyrou (2007). Chemical parameters of supernatant were determined using APHA (2012). A suspension containing water and soil sample in 1:1 ratio was also prepared followed by determination of $\mathrm{pH}$ and electrical conductivity of supernatant.

The method described by Boyd and Tucker (1993) was used to determine water soluble (WS) phosphorous of soil. The method involved shaking soil sample $(2 \mathrm{~g})$ in $100 \mathrm{ml}$ distilled water for 24 hours followed by centrifugation of soil suspension and collection of clear supernatant. ISO 11466 method based on digestion of soil sample with aqua regia was used (ISO, 1997) to extract total phosphorus (TP) adsorbed on soil particles. Available phosphorous (Olsen phosphorous) was extracted following Pansu and Gautheyrou (2007) using sodium carbonate solution (0.5 M, pH 8.5). Extracted phosphorous content was measured by ascorbic acid method (APHA 2012).

\section{Statistical Analysis}

Normality and homogeneity of variance of experimental data was verified prior to analysis of variance. One-way analysis of variance followed by post hoc analysis (significance level .05) was used to find significant differences in soil parameters measured at varying depth in ponds. Independent t test (significance level .05, two tailed) was used to compare the soil parameters observed for bottom soil of two groups of ponds at a specific depth. Correlation among soil parameters, pond age and soil depth was found through the use of Spearman's rho bivariate correlation analysis. Combined effect of pond age and soil depth on soil quality was determined using factorial (two way) analysis of variance with post hoc test. All statistical tests were performed using SPSS v. 22.

\section{Results and Discussion}

Data on bottom soil quality of ponds in two groups has been presented in Table 1 with statistical analysis. Distribution of soil physical and chemical attributes has been shown in Figure 2. Soil quality parameters of proposed sites for fish ponds have been presented in Table 2.

\section{Particle Size Distribution}

Surface soil sand content was significantly higher $(\mathrm{P}<.05)$ than deeper soil layers in both groups of ponds (Table 1). Surface soil sand content was $65.11 \%$ and 
Table 1. Soil quality parameters of bottom soil of ponds in two age groups (Mean \pm SE)

\begin{tabular}{|c|c|c|c|c|c|c|}
\hline \multirow{2}{*}{ Parameter } & \multicolumn{3}{|c|}{ Group 1 (23-32 years) } & \multicolumn{3}{|c|}{ Group 2 (8-20 years) } \\
\hline & Surface & $1 \mathrm{ft}$. & $2 \mathrm{ft}$. & Surface & $1 \mathrm{ft}$. & $2 \mathrm{ft}$. \\
\hline Sand (\%) & $31.05 \pm 4.77^{\mathrm{a}, \mathrm{x}}$ & $18.81 \pm 1.55^{\mathrm{b}, \mathrm{x}}$ & $16.68 \pm 0.68^{b, x}$ & $30.67 \pm 4.18^{a, x}$ & $15.33 \pm 3.58^{b, x}$ & $22.77 \pm 5.72^{a, b}$ \\
\hline Silt (\%) & $59.96 \pm 4.83^{a, x}$ & $60.43 \pm 3.56^{a, x}$ & $62.82 \pm 2.96^{a}$ & $58.92 \pm 3.35^{\mathrm{a}, \mathrm{x}}$ & $70.80 \pm 1.91^{b, y}$ & $63.83 \pm 4.77^{a, b}$ \\
\hline Clay (\%) & $8.99 \pm 1.22^{\mathrm{a}, \mathrm{x}}$ & $20.77 \pm 2.26^{b, x}$ & $20.50 \pm 3.03^{b, x}$ & $10.40 \pm 3.7^{\mathrm{a}, \mathrm{x}}$ & $13.86 \pm 2.28^{\mathrm{a}, \mathrm{Y}}$ & $13.40 \pm 1.88^{\mathrm{a}, \mathrm{Y}}$ \\
\hline $\mathrm{pH}(1: 1)$ & $7.87 \pm 0.18^{\mathrm{a}, \mathrm{x}}$ & $7.99 \pm 0.19^{a, b, x}$ & $8.27 \pm 0.17^{\mathrm{b}, \mathrm{x}}$ & $7.83 \pm 0.2^{\mathrm{a}, \mathrm{x}}$ & $8.00 \pm 0.54^{\mathrm{a}, \mathrm{x}}$ & $8.18 \pm 0.45^{a, x}$ \\
\hline $\mathrm{pH}(1: 2)$ & $7.64 \pm 0.19^{a, x}$ & $8.17 \pm 0.33^{b, x}$ & $8.22 \pm 0.3^{b, x}$ & $7.49 \pm 0.10^{\mathrm{a}, \mathrm{x}}$ & $7.86 \pm 0.07^{a, x}$ & $7.78 \pm 0.16^{\mathrm{a}, \mathrm{x}}$ \\
\hline Total alkalinity $\left(\mathrm{mgL}^{-1}\right)$ & $118.62 \pm 18.38^{\mathrm{a}, \mathrm{x}}$ & $126.20 \pm 13.26^{a, x}$ & $145.40 \pm 24.49^{a, x}$ & $119.23 \pm 24.67^{\mathrm{a}, \mathrm{x}}$ & $1133.27 \pm 226.63^{a, x}$ & $837.93 \pm 191.60^{a, x}$ \\
\hline $\mathrm{EC}\left(\mu \mathrm{Scm}^{-1}, 1: 1\right)$ & $4453.93 \pm 1325.42^{\mathrm{a}, \mathrm{x}}$ & $898.80 \pm 159.38^{b, x}$ & $756.13 \pm 112.97^{b, x}$ & $3028.0 \pm 490.29^{a, x}$ & $129.63 \pm 22.26^{b, Y}$ & $134.23 \pm 24.08^{b, x}$ \\
\hline $\mathrm{EC}\left(\mu \mathrm{Scm}^{-1}, 1: 2\right)$ & $3633.87 \pm 1204.6^{a, x}$ & $660.07 \pm 119.64^{b, x}$ & $516.73 \pm 88.22^{b, x}$ & $2548.3 \pm 521.66^{a, x}$ & $44.0 \pm 14.2^{b, x}$ & $45.00 \pm 17.57^{b, y}$ \\
\hline Chloride $\left(\mathrm{mgL}^{-1}\right)$ & $87.66 \pm 19.75^{a, x}$ & $28.94 \pm 4.82^{b, x}$ & $30.55 \pm 6.62^{b, x}$ & $71.78 \pm 24.25^{\mathrm{a}, \mathrm{x}}$ & $8.0 \pm 0.22^{a, x}$ & $8.18 \pm 0.19^{a, x}$ \\
\hline Water Soluble $\mathrm{P}\left(\mathrm{mgL}^{-}{ }^{-}\right)$ & $4.84 \pm 0.38^{\mathrm{a}, \mathrm{x}}$ & $17.49 \pm 7.61^{b, x}$ & $13.48 \pm 6.25^{a, b, x}$ & $15.75 \pm 2.76^{\mathrm{a}, \mathrm{y}}$ & $1298.13 \pm 227.43^{a, x}$ & $1075.40 \pm 245.70^{\mathrm{a}, \mathrm{x}}$ \\
\hline Available $\mathrm{P}\left(\mathrm{mgL}^{-1}\right)$ & $10.63 \pm 0.91^{\mathrm{a}, \mathrm{x}}$ & $12.70 \pm 3.31^{\mathrm{a}, \mathrm{x}}$ & $8.82 \pm 2.60^{a, x}$ & $10.60 \pm 1.50^{a, x}$ & $18.17 \pm 4.28^{\mathrm{a}, \mathrm{x}}$ & $9.79 \pm 3.58^{a, x}$ \\
\hline Total P $\left(\mathrm{mgL}^{-1}\right)$ & $427.33 \pm 46.12^{\mathrm{a}, \mathrm{x}}$ & $381.64 \pm 39.65^{a, x}$ & $325.23 \pm 52.60^{\mathrm{a}, \mathrm{x}}$ & $463.04 \pm 103.88^{a, x}$ & $572.82 \pm 49.28^{a, Y}$ & $432.84 \pm 66.61^{a, x}$ \\
\hline Organic carbon (\%) & $3.35 \pm 0.34^{\mathrm{a}, \mathrm{x}}$ & $2.03 \pm 0.44^{b, x}$ & $2.15 \pm 0.34^{b, x}$ & $2.60 \pm 0.27^{a, y}$ & $8.53 \pm 2.69^{b, x}$ & $7.31 \pm 2.47^{b, Y}$ \\
\hline
\end{tabular}

Note: Alphabets a-c show the results of one-way ANOVA. Means that do not share a similar letter in the same row for each group are significantly different ( $P<.05)$. Letter $\mathrm{X}, \mathrm{Y}$ show the results of $\mathrm{t}$ test comparing soil of similar depth collected from ponds of two groups. Means (for the soil parameter related to the same depth in either groups) that do not show a similar letter are significantly different $(P<.05)$
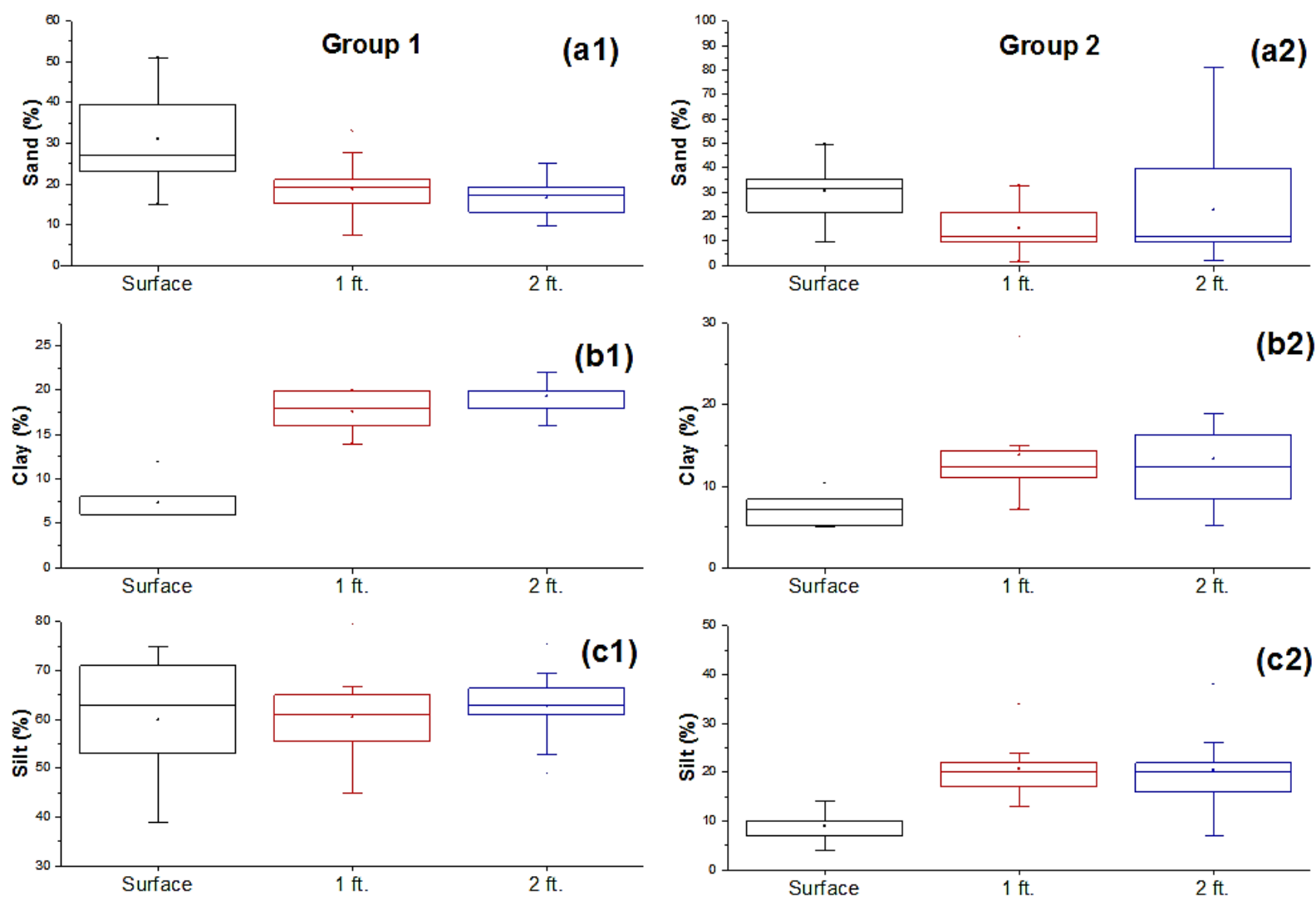

Figure 2: Distribution of a) sand, b) clay and c) silt in bottom soil of two Groups of ponds 
Group 1
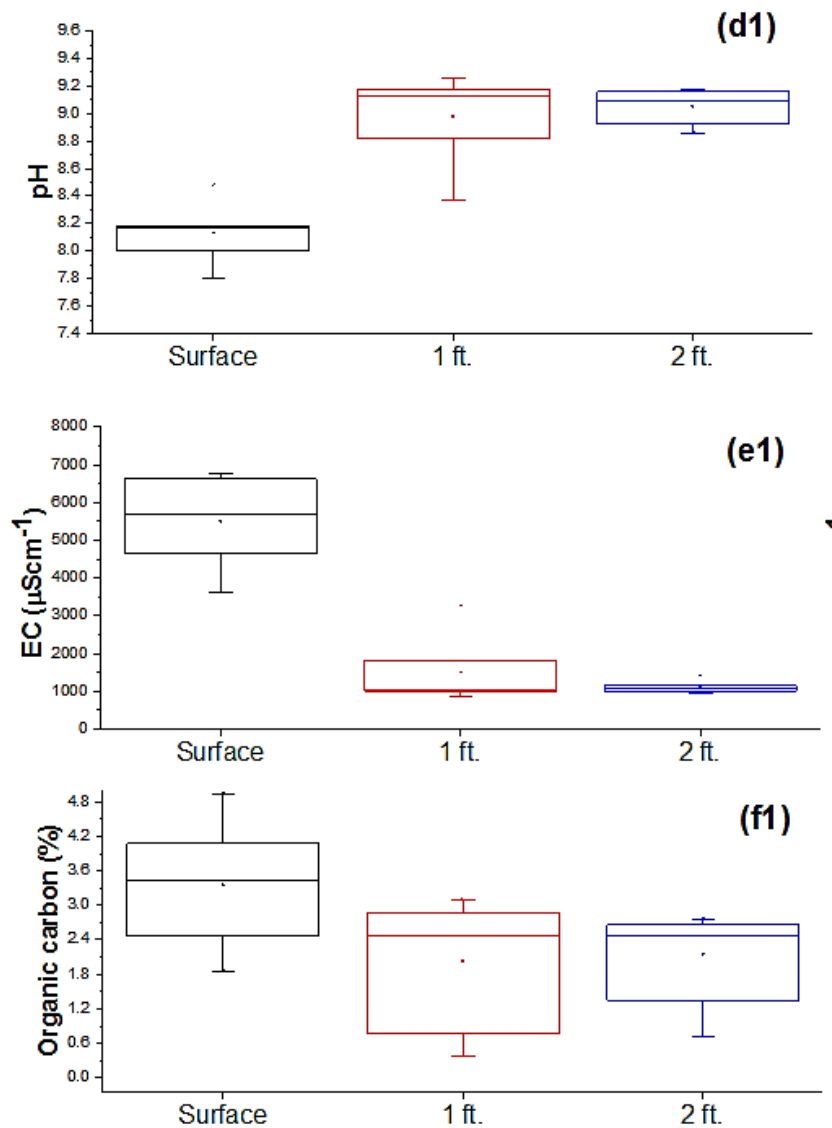

Group 2
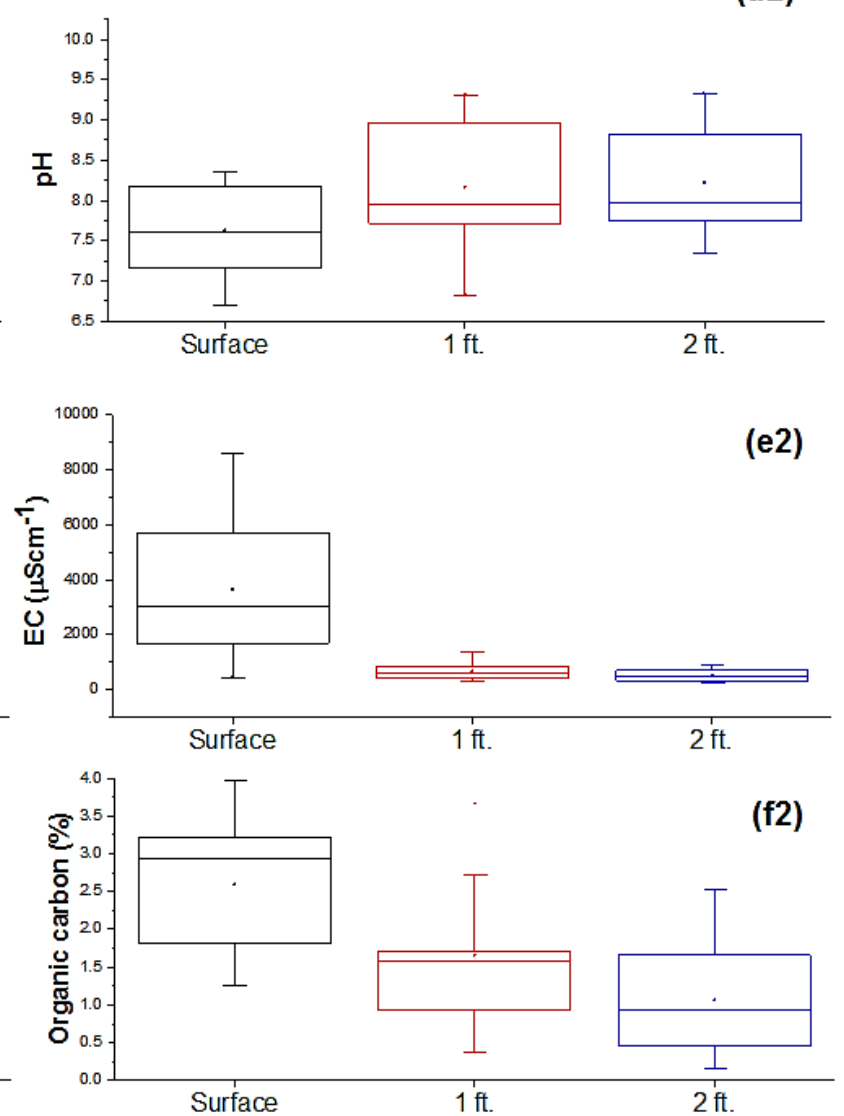

(f2)

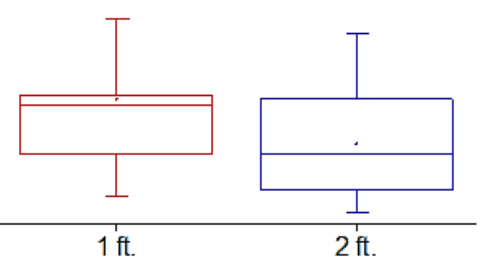

Figure 2 continued: Distribution of d) pH, e) EC and f) organic carbon in bottom soil of two Groups of ponds
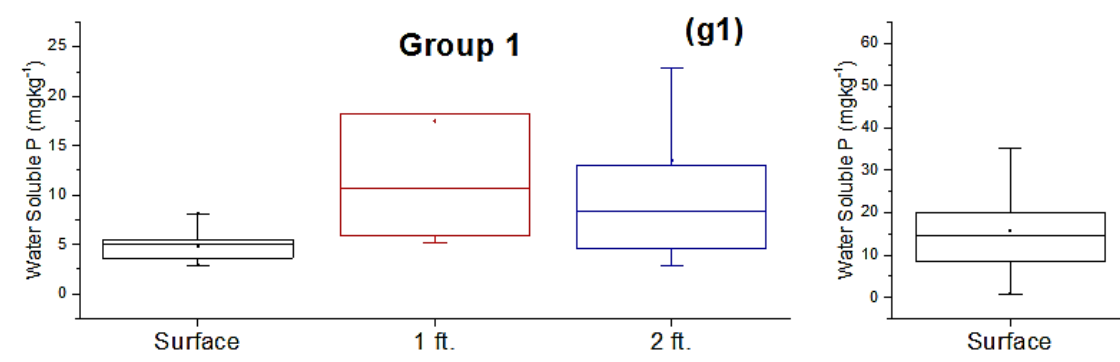

Group 2

(g2)


(i1)

Figure 2 continued: Distribution of $\mathrm{g}$ ) water soluble $\mathrm{P}, \mathrm{h}$ ) available $\mathrm{P}$ and i) total $\mathrm{P}$ in bottom soil of two Groups of ponds 
$100.10 \%$ higher than soil at $1 \mathrm{ft}$. depth in bottom soil of Group 1 and Group 2 ponds respectively. However, difference between sand content of soil at $1 \mathrm{ft}$. and $2 \mathrm{ft}$. was not significant in both groups (Table 1). Clay content was significantly lower in surface soil of Group 1 ponds than deeper layers. In ponds of Group 1, clay content was $52.35 \%, 225.73 \%, 126.56 \%, 206.91 \%$ and $108.79 \%$ higher in soil at1 $\mathrm{ft}$. than surface soil in LHR1-LHR5. In ponds of Group 2, clay content was $160.09 \%$, 30.65\%, $75.52 \%$ and $55.60 \%$ higher in deeper soil layers in LHR 6, LHR7, LHR9 and LHR10. In contrast to sand and clay, silt content did not show any significant difference in soil at varying depth. Relative distribution of sand, clay and silt particles in ponds of different ages has been shown in Figure 2 a-c at varying soil depths. Soil texture class was found to be silt loam in $70 \%$ to $80 \%$ of soil samples of both groups. Wudtisin and Boyd (2006) reported soil texture class to be silty clay loam in most of the ponds used for carp, catfish and prawn culture in Thailand.

In a newly constructed fish pond, original distribution of soil particles is disturbed during fish culture due to continuous suspension and deposition of soil owing to biological activity and water movement. According to Boyd's investigation (1976), maximum sand and gravel particles were deposited in pond areas where water level was $0.75 \mathrm{~m}$ to $1.50 \mathrm{~m}$. Results of present study are in agreement with those of Boyd and one of our earlier research (unpublished data) that also showed higher sand content in surface soil of old age ponds of Sargodha district, Pakistan. Our results, however, do not agree with those of Siddique et al. (2012) who found increasing level of silt and clay particles in pond soil with increasing pond age.

\section{Soil Physico-chemical Parameters}

Soil $\mathrm{pH}(1: 2)$ at the surface was significantly low $(\mathrm{P}<.05)$ than $\mathrm{pH}$ of deeper soil in ponds of Group 1 , however, there was no significant difference in $\mathrm{pH}$ of soil layers in ponds of Group 2. There was, also, no significant difference in soil total alkalinity found at varying soil depth in both group of ponds. Average $\mathrm{pH}$ was higher than 7.0 in surface soil of ponds of both groups and an increase in $\mathrm{pH}$ was observed with increasing soil depth. Figure $2 \mathrm{~d}$ shows distribution of soil $\mathrm{pH}$ at various depth in bottom of different age ponds.

$\mathrm{pH}$ of bottom soil of aquaculture ponds is recommended to be 7.5-8.0 (1:1) at which microbial activity is optimum (Boyd \& Pippopinyo, 1994). Surface soil $\mathrm{pH}$ of most of the ponds was found to be within suitable range and indicated the calcareous nature of soil. Observed soil pH also ruled out the necessity to lime ponds for neutralizing soil acidity. Total alkalinity of soil depends upon the relative amounts of carbonates, bicarbonates and hydroxides in the soil, each of which contributes differently to soil extract's $\mathrm{pH}$. In present study, average soil extract's pH (7.5-8.5) indicates the presence of bicarbonates in soil (Wachinski, 2017). Thunjai et al. (2004) reported soil pH to be 6.62-7.90 for tilapia ponds in Thailand and attributed high $\mathrm{pH}$ to excessive application of liming material. Boyd et al. (1994) found soil $\mathrm{pH}$ to be $6.96 \pm 0.76$ in freshwater ponds and $6.55 \pm 1.49$ in brackish water ponds. According to Wudtisin and Boyd (2006), no significant difference in soil $\mathrm{pH}$ was found in ponds used for carp, catfish and prawns culture.

Table 2. Particle size distribution and physico-chemical parameters of soil at four proposed sites for fish ponds (Mean \pm SE)

\begin{tabular}{|c|c|c|c|c|c|}
\hline \multirow{2}{*}{$\begin{array}{l}\text { Sampling } \\
\text { Sites }\end{array}$} & \multirow{2}{*}{ Parameter } & \multicolumn{3}{|c|}{ Soil depth } & \multirow[b]{2}{*}{$3 \mathrm{ft}$. } \\
\hline & & Surface & $1 \mathrm{ft}$. & $2 \mathrm{ft}$. & \\
\hline \multirow{5}{*}{ Site 1} & Sand (\%) & $22.90 \pm 2.01^{\mathrm{a}}$ & $22.19 \pm 2.34^{a}$ & $20.82 \pm 3.46^{a}$ & $20.17 \pm 4.64^{a}$ \\
\hline & Silt (\%) & $49.94 \pm 2.01^{\mathrm{a}}$ & $49.96 \pm 3.97$ a & $51.32 \pm 4.17^{a}$ & $51.98 \pm 7.22^{\mathrm{a}}$ \\
\hline & Clay (\%) & $27.17 \pm 0.02^{\mathrm{a}}$ & $27.85 \pm 6.12^{\mathrm{a}}$ & $27.86 \pm 7.57^{a}$ & $27.85 \pm 7.57^{a}$ \\
\hline & $\mathrm{pH}$ & $8.48 \pm 0.48^{a}$ & $8.37 \pm 0.88^{a}$ & $8.59 \pm 0.65^{a}$ & $8.61 \pm 0.72^{a}$ \\
\hline & EC & $388.67 \pm 88.82^{a}$ & $472.33 \pm 99.20^{a}$ & $508.67 \pm 164.63^{a}$ & $554.00 \pm 258.97$ \\
\hline \multirow{5}{*}{ Site 2} & Sand (\%) & $73.0 \pm 18.0^{a}$ & $76.95 \pm 3.06^{a}$ & $84.28 \pm 4.15^{a}$ & $80.95 \pm 6.42^{a}$ \\
\hline & Silt (\%) & $15.3 \pm 11.7^{\mathrm{a}}$ & $13.99 \pm 1.99$ a & $9.99 \pm 4.00^{\mathrm{a}}$ & $13.32 \pm 4.16^{\mathrm{a}}$ \\
\hline & Clay (\%) & $11.7 \pm 7.6^{a}$ & $9.06 \pm 3.05^{a}$ & $5.73 \pm 1.15^{a}$ & $5.73 \pm 3.05^{a}$ \\
\hline & $\mathrm{pH}$ & $7.9 \pm 0.2^{\mathrm{a}}$ & $8.06 \pm 0.82$ a & $8.29 \pm 0.63^{a}$ & $8.07 \pm 0.54$ a \\
\hline & $\mathrm{EC}$ & $322.0 \pm 96.8^{a}$ & $449.67 \pm 346.00^{a}$ & $498.33 \pm 364.40^{a}$ & $396.67 \pm 215.19$ \\
\hline \multirow{5}{*}{ Site 3} & Sand (\%) & $45.12 \pm 37.60^{a}$ & $63.08 \pm 45.62^{\mathrm{a}}$ & $45.15 \pm 35.95^{a}$ & $55.79 \pm 13.03^{a}$ \\
\hline & Silt (\%) & $46.28 \pm 34.97^{a}$ & $28.66 \pm 40.13^{a}$ & $44.93 \pm 31.28^{a}$ & $35.62 \pm 19.21^{a}$ \\
\hline & Clay (\%) & $8.590 \pm 2.636^{a}$ & $8.26 \pm 5.51^{a}$ & $9.92 \pm 8.36^{a}$ & $8.59 \pm 6.93^{a}$ \\
\hline & $\mathrm{pH}$ & $7.717 \pm 0.121^{\mathrm{a}}$ & $7.71 \pm 0.12^{\mathrm{a}}$ & $7.73 \pm 0.11^{\mathrm{a}}$ & $7.77 \pm 0.04^{a}$ \\
\hline & EC & $314.3 \pm 74.22^{\mathrm{a}}$ & $333.33 \pm 134.69^{a}$ & $340.07 \pm 249.48^{a}$ & $251.67 \pm 20.11^{a}$ \\
\hline \multirow{5}{*}{ Site 4} & Sand (\%) & $64.04 \pm 2.54^{\mathrm{a}}$ & $65.66 \pm 0.02^{a}$ & $69.76 \pm 6.86^{a}$ & $70.39 \pm 4.51^{a}$ \\
\hline & Silt (\%) & $29.25 \pm 3.07^{a}$ & $28.62 \pm 0.56^{a}$ & $24.21 \pm 6.29 a^{a}$ & $22.91 \pm 3.38^{a}$ \\
\hline & Clay (\%) & $6.71 \pm 0.57^{a}$ & $5.72 \pm 0.58^{a}$ & $6.03 \pm 0.57^{a}$ & $6.71 \pm 1.13^{a}$ \\
\hline & $\mathrm{pH}$ & $7.74 \pm 0.13^{\mathrm{a}}$ & $7.62 \pm 0.19^{a}$ & $7.61 \pm 0.15^{\mathrm{a}}$ & $7.79 \pm 0.11^{\mathrm{a}}$ \\
\hline & $\mathrm{EC}$ & $197.57 \pm 29.93^{a}$ & $204.20 \pm 77.24^{a}$ & $132.93 \pm 23.27^{a}$ & $163.03 \pm 18.08^{a}$ \\
\hline
\end{tabular}

Note: Means that share a similar letter in the same row are statistically non-significant $(P<.05)$. 
Surface soil electrical conductivity (EC) in ponds of Group 1 and Group 2 was significantly higher than that of deeper soil ( $P<.001$ for Group 1 and $<.01$ for Group 2). However, there was no significant difference between soil EC found at $1 \mathrm{ft}$. and $2 \mathrm{ft}$. depth in both groups. Surface soil chloride content was significantly higher than that of soil at $1 \mathrm{ft}$. and $2 \mathrm{ft} .(P<.001)$ in the case of Group 1 ponds. No significant difference in chloride content with varying soil depth was found in ponds of Group 2. According to classification of Dellavalle (1992), surface soil of ponds was found to be either very strongly saline or saline and deeper soil ( $1 \mathrm{ft}$. and $2 \mathrm{ft}$.) was slightly saline, moderately saline or non-saline on the basis of observed soil EC. Distribution of soil EC in surface and deeper layers can be visualized from Figure 2e. Difference between EC of surface and deeper soil was higher for ponds of Group 1 than ponds of Group 2. As Group 1 included old age ponds compared to Group 2 , the results implied that continuous use of ponds for fish culture can cause increase in surface soil EC.

Soil physico-chemical parameters were analysed using two different types of extracts (1:1 and 1:2) to assess effect of dilution on solubility of soil adsorbents. For most of the samples, $\mathrm{pH}$ and EC of soil extract decreased with increase in water volume used for extraction; an effect that is expected with dilution. However, there were a number of soil samples in which these parameters actually increased with dilution. This observation clearly indicated that for these samples, water volume used in 1:1 extract was not able to dissolve all the soil adsorbents due to solvent's saturation. It is a key finding which suggests that soil $\mathrm{pH}$ and EC should be monitored in 1:2 extract to ensure dissolution of all the ions sorbed on soil particles.

\section{Soil Organic Carbon}

Soil organic carbon content was significantly high in surface soil than deeper soil $(P<.01)$. However, there was no significant difference between organic carbon of soil at $1 \mathrm{ft}$. and $2 \mathrm{ft}$. Independent t test showed significant difference in surface organic carbon of two groups of ponds $(P<.05)$ with higher content found for Group 1 ponds (3.35\% $\pm 0.34 \%)$ compared to Group 2 ponds $(2.60 \% \pm 0.27 \%)$. Figure $2 f$ shows distribution of soil organic carbon at varying depths.

Organic carbon of pond bottom soil is recommended to be $1.0 \%-3.0 \%$ (Boyd, Queiroz, et al. 2002) which is essential for growth of benthic organisms and microbial activity in pond bottom (Xinglong \& Boyd, 2006). Higher organic carbon in older age ponds found in present study supports a number of earlier investigations (Munsiri et al. 1995; Sonnenholzner \& Boyd, 2000; Steeby et al., 2004; Rana et al. 2017) which reported organic matter stratification with varying soil depth in pond bottom soil. Rana et al. (2017) found increase in soil organic carbon with pond age $(1.76 \% \pm 0.5 \%$ in $1-5$ years ponds and $1.98 \% \pm 0.3 \%$ in $6-10$ years old ponds). According to Yuvanatemiya and Boyd
(2006), sediment removal can significantly affect organic carbon reservoir of the soil. If pond's surface sediment is removed to expose original soil, the farmers must ensure addition of organic matter due to low organic carbon in deeper soil layers.

\section{Soil Phosphorous}

Water soluble (WS) phosphorous represents phosphorous soluble in water at neutral to slightly acidic $\mathrm{pH}$ ( $\mathrm{pH}$ of distilled water) and indicates expected threshold of phosphorous deficiency in soil solution. In present study, WS phosphorous was significantly low in surface soil layer of old age ponds of Group 1. Figure $2 \mathrm{~g}$ shows that surface soil WS phosphorous in Group 1 ponds was less than $10 \mathrm{mgkg}^{-1}$ in all the samples. However, it was greater than $10 \mathrm{mgkg}^{-1}$ in $50 \%$ of samples collected from soil at $1 \mathrm{ft}$. It is also apparent from the Figure $2 \mathrm{~g}$ that difference in WS phosphorous of soil at varying depth was not so pronounced in the case of Group 2 ponds. This observation was also supported by independent $t$ - test that revealed significant difference in surface WS phosphorous content of two group of ponds.

There was no significant difference in total phosphorous content of soil at varying depth in ponds of Group 1 and Group 2. However, total phosphorous content of soil at $1 \mathrm{ft}$. was significantly high in ponds of Group 2 compared to Group 1 as shown by t test. No significant difference in soil available phosphorous content with varying soil depth was found in two group of ponds. Figure $2 \mathrm{~h}$ and $2 \mathrm{i}$ shows the distribution of available phosphorous and total phosphorous in soil of two groups of ponds.

Most of the phosphorous applied to ponds in the form of fertilizers is adsorbed on the soil. A comparison of water soluble phosphorous, available phosphorous and total phosphorous showed that soluble phosphorous fraction is only $1-10 \%$ of total phosphorous adsorbed on soil. That's why soil total phosphorous content is reported to increase with pond age. Tapader et al. (2017) analyzed bottom soil quality of recently constructed ponds (one to five years old) and older ponds (greater than five years old) in Nokhali, Bangladesh. Authors reported that in contrast to soil $\mathrm{pH}$, organic matter, nitrogen and sulpher levels that were found to decrease with pond age, soil phosphorous content increased. Munsiri et al. (1995) reported total phosphorous content to be $1617 \mathrm{mgkg}^{-1} \pm 120 \mathrm{mgkg}^{-1}$, $2530 \mathrm{mgkg}^{-1} \pm 252 \mathrm{mgkg}^{-1}$ and $1733 \mathrm{mgkg}^{-1} \pm 102 \mathrm{mgkg}^{-1}$ in 2 years, 23 years and 52 years old fish ponds respectively.

According to present investigation, soil total phosphorous content did not differ significantly in 8-20 years and 23-32 years old ponds. This observation can be attributed to the leaching of phosphorous compounds through porous soil particulates to deeper soil layers. According to Masuda and Boyd (1994) that 
phosphorous can leach through surface soil and collect in deeper $(20-40 \mathrm{~cm})$ soil layers of ponds.

\section{Soil Quality of Proposed Fish Ponds Sites}

In order to verify that surface soil quality in ponds of both groups was due to the effect of aquaculture activities, we selected four sites that were proposed to be used for fish pond construction and determined the soil quality at varying depth. Results for soil quality attribute at these sites have been presented in Table 2 starting from surface up to the depth of $3 \mathrm{ft}$. Statistical analysis showed that none of the soil quality parameters (particle size distribution, $\mathrm{pH}, \mathrm{EC}$ ) varied with depth at these sites. In other words, surface soil quality did not vary significantly $(\mathrm{P}<.05)$ compared to deeper soil layers. It can, therefore, be inferred that soil parameters do not show stratification with depth at a site which is not used for fish farming activity. This finding supported the results of present study that use of a site for aquaculture can lead to deposition of a surface sediment which can have significantly different characteristics than that of original pond soil.

\section{Correlation Analysis}

Results of Spearman's bivariate correlation have been presented in Table 3. It was interesting to note that EC of soil (both in 1:1 and 1:2 extract) and chloride content were negatively correlated with clay particles while positively correlated with sand content. Significant positive correlation was present between clay content and $\mathrm{pH}$ (both in 1:1 and 1:2 extract) as well as total alkalinity. It was also noteworthy that organic carbon content was positively correlated with pond age while negatively related with soil depth i.e. increase in pond age led to increased organic matter content of soil which decreased with increasing soil depth. A strong negative correlation between soil depth and sand content implied that sand particles were more abundant in surface soil than deeper layers. In line with that, a significant positive correlation between soil depth and clay content led to the conclusion that in old age ponds, clay content of surface soil becomes low as compared to deeper soil layers. A strong positive correlation found between soil EC and chloride content; spearman's $r=$ $.532, p$ (two tailed) $=<.001$, indicated that chloride ions were one of the major ions contributing to soil salinity and shared $28.30 \%$ of its variability (coefficient of determination; $\mathrm{R}^{2}=.283$ ).

Correlation analysis showed that there was positive correlation between soil $\mathrm{pH}$ and water soluble phosphorous $(\mathrm{P}<.001)$ and negatively correlation between $\mathrm{pH}$ and available phosphorous $(\mathrm{P}<.01)$. The results are in agreement with our earlier investigation (unpublished data) in which similar correlation was found between soil $\mathrm{pH}$ and phosphorous content of bottom soil of brackish water ponds in Sargodha district, Punjab, Pakistan. It appears from these findings that increase in soil $\mathrm{pH}$ causes higher dissolution of phosphorous solubilized at neutral to slightly acidic $\mathrm{pH}$ (WS phosphorous) while decreased solubility of phosphorous compounds extracted at pH 8.5 (available phosphorous).

\section{Factorial Analysis}

In order to determine interactive effect of soil depth and pond age on pond soil quality, two-way analysis of variance was used. Visual display of combined effect of pond age and soil depth on soil quality parameters is presented in Figure 3. Statistical parameters for two-way ANOVA have been presented in Table 4 and described below.

i. There was a significant interactive effect of the soil depth and pond age on soil EC and clay content

ii. Soil clay content was low in 23-32 years ponds than 08-32 years ponds. Moreover, difference in clay content of soil at varying depth was more pronounced for older ponds.

iii. Although soil EC did not differ significantly with pond age, combined effect of pond age and soil depth on EC was significant. Surface soil EC was significantly high in 23-32 years old ponds than in 8-20 years old ponds. However, reverse was true at deeper sites.

\section{Conclusion}

Present study has shown that aquaculture can have a significant impact on surface soil quality of fish ponds depending on pond age. Findings of present study have led to the derivatization of following conclusions that must be considered in fish pond management for sustainable development of aquaculture.

1. Aquaculture activities can lead to the deposition of a surface sediment over the original pond bottom soil; the quality parameters of sediment can be significantly different than that of original pond soil.

2. Continuous use of ponds for fish culture can lead to redistribution of soil particulates with higher sand and lower clay content in surface compared to original soil. This disturbance in soil particle size distribution can lead to excessive water seepage and reduced nutrient holding capacity of surface soil.

3. Physico-chemical parameters of soil should be investigated using 1:2 soil water extract to ensure complete extraction of sorbed chemicals.

4. Soil in Lahore district, Punjab, Pakistan is calcareous in nature, thereby, lime should be used for soil disinfection purposes only.

5. Salinity of surface soil sediment can significantly increase with pond age and can 
Table 3. Correlation matrix of soil quality parameters, pond age and soil depth

\begin{tabular}{|c|c|c|c|c|c|c|c|c|c|c|c|c|c|c|c|c|}
\hline & & Pond Age & Soil Depth & Sand & Silt & Clay & $\begin{array}{l}\text { Organic } \\
\text { carbon }\end{array}$ & $\mathrm{pH}(1: 2)$ & $\mathrm{EC}(1: 2)$ & Total alkalinity & Chloride & $\mathrm{pH}(1: 1)$ & $\mathrm{EC}(1: 1)$ & $\begin{array}{c}\text { Water } \\
\text { Soluble P }\end{array}$ & Total P & Available $\mathrm{P}$ \\
\hline \multirow{2}{*}{ Pond Age } & $r_{s}$ & 1.000 & 0.000 & .065 & $-.218^{*}$ & $.293^{* *}$ & $.318^{* *}$ & $.278^{* *}$ & -.190 & .065 & -.044 & .062 & -.112 & $-.220^{*}$ & $-.348^{* *}$ & .177 \\
\hline & Sig. & & 1.000 & .545 & .039 & .005 & .002 & .008 & .072 & .544 & .682 & .564 & .291 & .037 & .001 & .094 \\
\hline \multirow{2}{*}{ Soil Depth } & $r_{s}$ & & 1.000 & $-.472^{* *}$ & $.217^{*}$ & $.458^{* *}$ & $-.495^{* *}$ & $.283^{* *}$ & $-.638^{* *}$ & $.252^{*}$ & $-.335^{* *}$ & $.310^{* *}$ & $-.641^{* *}$ & .079 & -.140 & $-.226^{*}$ \\
\hline & Sig. & & & .000 & .040 & .000 & .000 & .007 & .000 & .016 & .001 & .003 & .000 & .462 & .189 & .032 \\
\hline \multirow{2}{*}{ Sand } & $r_{s}$ & & & 1.000 & $-.723^{* *}$ & $-.576^{* *}$ & .174 & -.133 & $.533^{* *}$ & $-.220^{*}$ & $.488^{* *}$ & -.203 & $.544^{* *}$ & -.074 & .027 & $.317^{* *}$ \\
\hline & Sig. & & & & .000 & .000 & .101 & .211 & .000 & .037 & .000 & .055 & .000 & .490 & .801 & .002 \\
\hline \multirow{2}{*}{ Silt } & $r_{s}$ & & & & 1.000 & -.050 & -.165 & -.121 & -.192 & -.062 & $-.237^{*}$ & -.119 & $-.230^{*}$ & -.163 & .010 & $-.369^{* *}$ \\
\hline & Sig. & & & & & .641 & .120 & .256 & .070 & .559 & .025 & .263 & .030 & .125 & .927 & .000 \\
\hline \multirow{2}{*}{ Clay } & $r_{s}$ & & & & & 1.000 & -.060 & $.357^{* *}$ & $-.666^{* *}$ & $.427^{* *}$ & $-.553^{* *}$ & $.412^{* *}$ & $-.597^{* *}$ & $.286^{* *}$ & -.054 & -.008 \\
\hline & Sig. & & & & & & .577 & .001 & .000 & .000 & .000 & .000 & .000 & .006 & .614 & .943 \\
\hline \multirow{2}{*}{$\begin{array}{l}\text { Organic } \\
\text { carbon }\end{array}$} & $r_{s}$ & & & & & & 1.000 & $-.362^{* *}$ & $.255^{*}$ & $-.213^{*}$ & .029 & $-.298^{* *}$ & $.332^{* *}$ & -.186 & -.089 & $.304^{* *}$ \\
\hline & Sig. & & & & & & & .000 & .015 & .044 & .783 & .004 & .001 & .079 & .402 & .004 \\
\hline \multirow{2}{*}{$\mathrm{pH}(1: 2)$} & $r_{s}$ & & & & & & & 1.000 & $-.313^{* *}$ & $.393^{* *}$ & -.001 & $.495^{* *}$ & $-.321^{* *}$ & .178 & .098 & -.014 \\
\hline & Sig. & & & & & & & & .003 & .000 & .995 & .000 & .002 & .094 & .356 & .893 \\
\hline \multirow{2}{*}{ EC $(1: 2)$} & $r_{s}$ & & & & & & & & 1.000 & $-.278^{* *}$ & $.684^{* *}$ & $-.275^{* *}$ & $.889^{* *}$ & -.159 & .154 & $.280^{* *}$ \\
\hline & Sig. & & & & & & & & & .008 & .000 & .009 & .000 & .135 & .148 & .007 \\
\hline \multirow{2}{*}{ Total alkalinity } & $r_{s}$ & & & & & & & & & 1.000 & -.155 & $.568^{* *}$ & $-.286^{* *}$ & $.363^{* *}$ & .031 & -.196 \\
\hline & Sig. & & & & & & & & & & .144 & .000 & .006 & .000 & .773 & .064 \\
\hline \multirow{2}{*}{ Chloride } & $r_{s}$ & & & & & & & & & & 1.000 & -.163 & $.562^{* *}$ & -.144 & -.053 & .127 \\
\hline & Sig. & & & & & & & & & & & .126 & .000 & .175 & .623 & .232 \\
\hline \multirow{2}{*}{$\mathrm{pH}(1: 1)$} & $r_{s}$ & & & & & & & & & & & 1.000 & $-.394^{* *}$ & $.311^{* *}$ & -.063 & -.181 \\
\hline & Sig. & & & & & & & & & & & & .000 & .003 & .555 & .088 \\
\hline \multirow{2}{*}{ EC $(1: 1)$} & $r_{s}$ & & & & & & & & & & & & 1.000 & -.188 & .151 & $.321^{* *}$ \\
\hline & Sig. & & & & & & & & & & & & & .076 & .155 & .002 \\
\hline \multirow{2}{*}{$\begin{array}{c}\text { Water soluble } \\
\mathrm{P}\end{array}$} & $r_{s}$ & & & & & & & & & & & & & 1.000 & .181 & .142 \\
\hline & Sig. & & & & & & & & & & & & & & .087 & .182 \\
\hline \multirow{2}{*}{ Total P } & $r_{s}$ & & & & & & & & & & & & & & 1.000 & $.225^{*}$ \\
\hline & Sig. & & & & & & & & & & & & & & & .033 \\
\hline \multirow{2}{*}{ Available P } & $r_{s}$ & & & & & & & & & & & & & & & 1.000 \\
\hline & Sig. & & & & & & & & & & & & & & & \\
\hline
\end{tabular}



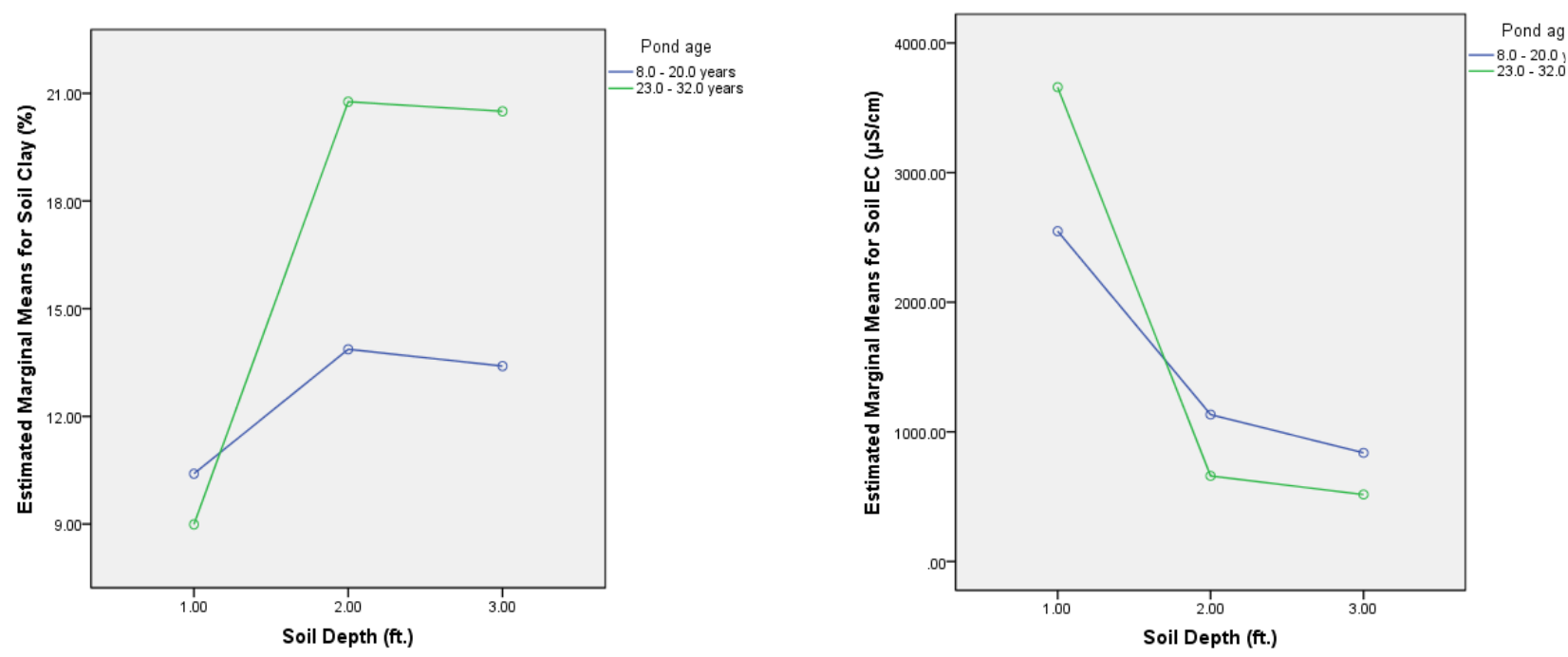

Figure 3: Interactive effect of soil depth and pond age on a) soil clay content, b) soil EC

Table 4. Results of two-way analysis of variance showing interactive effect of pond age and soil depth on soil parameters

\begin{tabular}{lccc|ccc}
\hline \multirow{2}{*}{ Statistical parameter } & \multicolumn{3}{c|}{ Clay content } & \multicolumn{3}{c}{ Electrical conductivity } \\
\cline { 2 - 7 } & Pond age & Soil depth & Interactive effect & Pond age & Soil depth & Interactive effect \\
\hline $\mathrm{F}$ & $10.37(1,90)$ & $14.52(2,90)$ & $4.64(2,90)$ & $0.158(1,90)$ & $34.17(2,90)$ & $3.62(2,90)$ \\
\hline$p$ & .002 & .000 & .012 & .692 & .000 & .031 \\
\hline
\end{tabular}

even raise to threatening levels (for fish production) if nature of soil is already saline.

6. Soil extractable phosphorous represents only about $1 \%-10 \%$ of total soil phosphorous reservoir that necessitates regular addition of phosphorous fertilizers to compensate for fraction of this primary nutrient strongly adsorbed on soil.

7. Regular removal of surface sediment with unsuitable particle size distribution and high salinity can expose the original pond bottom soil with optimum soil quality parameters.

8. Organic carbon content of soil exposed after sediment removal will be lower than that of sediment, therefore, addition of organic matter must be ensured to keep it within suitable limits.

9.

In future, there is need to investigate bottom soil quality of operational fish ponds to assess accumulation of toxic substances in it (e.g. heavy metals and pesticides) that may bioaccumulate in fish muscles and pose significant threat to human health.

\section{Ethical Statement}

The study is not directly based on animals, therefore, provision of ethical statement is not applicable.

\section{Funding Information}

This research did not receive any specific funding.

\section{Author Contribution}

JS planned the research study, conducted the experimental work and prepared \& revised the manuscript. KNW supervised the research project. ZSM helped in data interpretation and statistical analysis. $M Z$ provided technical support for the project.

\section{Conflict of Interest}

The authors declare no conflict of interest.

\section{References}

APHA. (2012). Standard methods for the examination of water and wastewater $\left(7^{\text {th }}\right.$ ed.). American Public Health Association.

Bentone, J.J. (2003). Agronomic handbook: Management of crops, soils, and their fertility. CRC Press.

Boyd, C.E. (1976). Chemical and textural properties of muds from different depths in ponds. Hydrobiologia, 48(2), 141-144. https://doi.org/10.1007/BF00040167

Boyd, C.E. (1995). Bottom soils, sediment, and pond aquaculture. Chapman \& Hall.

Boyd, C.E., \& Pippopinyo, S. (1994). Factors affecting respiration in dry pond bottom soils. Aquaculture, 120(34), 283-293.

https://doi.org/10.1016/0044-8486(94)90085-X

Boyd, C.E., Queiroz, J., \& Wood, C.W. (2002). Pond soil characteristics and dynamics of soil organic matter and nutrients. Sixteenth Annual Technical Report. Pond Dynamics/Aquaculture CRSP, Oregon State University, Corvallis, Oregon, 1-7. 
Boyd, C.E., Tanner, M.E., Madkour, M., \& Masuda, K. (1994). Chemical characteristics of bottom soils from freshwater and brackishwater aquaculture ponds. Journal of the World Aquaculture Society, 25(4), 517-534. https://doi.org/10.1111/j.1749-7345.1994.tb00821.x

Boyd, C.E., \& Tucker, C.S. (1993). Water quality and pond soil analyses for aquaculture. Alabama Agricultural Experiment Station, Auburn University.

Boyd, C.E., Wood, C., \& Thunjai, T. (2002). Aquaculture pond bottom soil quality management. Pond Dynamics/Aquaculture Collaborative Research Support Program.

Dellavalle, N. (1992). Determination of specific conductance in supernatant 1: 2 soil: water solution. In Handbook on reference methods for soil analysis. (pp. 44-50). Soil and Plant Analysis Council, Inc.

FAO (2020). The state of world fisheries and aquaculture 2020: Sustainability in action. Food and Agriculture Organization. Retrieved from http://www.fao.org/3/a-i5555e.pdf

Hayat, M. (2005). National aquaculture sector overview. Pakistan. National aquaculture sector overview fact sheets. Food and Agriculture Organization. Retrieved from http://www.fao.org/3/a-i5555e.pdf

ISO (1997). Soil quality - extraction of trace elements soluble in aqua regia. (ISO/ DIN standard no. 11466:1995).

Masuda, K., \& Boyd, C.E. (1994). Chemistry of sediment pore water in aquaculture ponds built on clayey ultisols at Auburn, Alabama. Journal of the World Aquaculture Society, 25(3), 396-404. https://doi.org/10.1111/j.1749-7345.1994.tb00223.x.

Munsiri, P., Boyd, C.E., \& Hajek, B.F. (1995). Physical and chemical characteristics of bottom soil profiles in ponds at Auburn, Alabama, USA and a proposed system for describing pond soil horizons. Journal of the World Aquaculture Society, 26(4), 346-377. https://doi.org/10.1111/j.1749-7345.1995.tb00831.x

Ndome, C., Udo, I., Akpan, I., \& Udom, C. (2012). Effect of water quality and bottom soil properties on the diversity and abundance of macrobenthic fauna in some tropical frow-out earthen fish ponds. Ecologia, 2(1), 12-22. http://doi.org/10.3923/ecologia.2012.12.22

Pansu, M., \& Gautheyrou, J. (2007). Handbook of soil analysis: Mineralogical, organic and inorganic methods. Springer Science \& Business Media.

Rana, M.E.U., Hossain, S., Tapader, M.A., Hossain, M.B., \& Sarker, B.S. (2017). Effects of pond age and depth on bottom soil nutrients, $\mathrm{pH}$ and salinity in commercial aquaculture farm. World Journal of Fish and Marine Sciences, 9(4), 25-30.

http://doi.org/10.5829/idosi.wjfms.2017.25.30

Siddique, M., Barua, P., \& Ghani, M. (2012). Comparative study of physico-chemical properties of soil according to the age of aquaculture pond of Bangladesh. Mesopotamian Journal of Marine Science, 27(1), 29-38.

Sonnenholzner, S., \& Boyd, C.E. (2000). Vertical gradients of organic matter concentration and respiration rate in pond bottom soils. Journal of the World Aquaculture Society, 31(3), 376-380.

https://doi.org/10.1111/j.1749-7345.2000.tb00887.x

Steeby, J.A., Hargreaves, J.A., Tucker, C.S., \& Kingsbury, S. (2004). Accumulation, organic carbon and dry matter concentration of sediment in commercial channel catfish ponds. Aquacultural Engineering, 30(3-4), 115-126. https://doi.org/10.1016/j.aquaeng.2003.10.001

Tapader, M.M.A., Hasan, M.M., Sarker, B.S., Enayet, M., Rana, U., \& Bhowmik, S. (2017). Comparison of soil nutrients, $\mathrm{pH}$ and electrical conductivity among fish ponds of different ages in Noakhali, Bangladesh. Korean Journal of Agricultural Science, 44(1), 016-022.

https://doi.org/10.7744/kjoas.20170002

The Workd Bank Group (2018). Revitalizing Pakistan's fisheries; Options for sustainable development. International Bank for Reconstruction and Development/ The World Bank.

Thunjai, T., Boyd, C.E., \& Boonyaratpalin, M. (2004). Bottom soil quality in tilapia ponds of different age in Thailand. Aquaculture Research, 35(7), 698-705. https://doi.org/10.1111/j.1365-2109.2004.01072.x

Wachinski, A.M. (2017). Environmental ion exchange: Principles and design (2nd ed.). CRC Press.

Wudtisin, I., \& Boyd, C.E. (2006). Physical and chemical characteristics of sediments in catfish, freshwater prawn and carp ponds in Thailand. Aquaculture Research, 37(12), 1202-1214. http://doi.org/10.1111/j.1365-2109.2006.01547.x

Xinglong, J., \& Boyd, C.E. (2006). Relationship between organic carbon concentration and potential pond bottom soil respiration. Aquacultural Engineering, 35(2), 147-151. https://doi.org/10.1016/j.aquaeng.2005.10.002

Yuvanatemiya, V., \& Boyd, C.E. (2006). Physical and chemical changes in aquaculture pond bottom soil resulting from sediment removal. Aquacultural Engineering, 35(2), 199205.

https://doi.org/10.1016/j.aquaeng.2006.02.001 